\title{
Establishment of arbuscular mycorrhizal fungi in autotrophic strawberry cultures in vitro. Comparison with inoculation of microplants in vivo
}

\author{
AC Cassells *, GL Mark, C Periappuram \\ Department of Plant Science, University College, Cork, Ireland
}

(Received 30 July 1996; accepted 23 September 1996)

\begin{abstract}
Summary - Mycorrhization has been demonstrated in a commercial autotrophic micropropagation system where it has been shown to improve the performance of Fragaria vesca microplants at acclimatization (weaning) and in subsequent development. The experiments described involved a comparison of microplants mycorrhized in vitro, and at establishment, with non-aseptic arbuscular mycorrhizal (AM) spores. It was shown that photosynthesis in vitro is not impaired by mycorrhization. There was no difference in mean percentage root colonization for in vitro and in vivo colonized microplants. Microplants, mycorrhized in vitro or in vivo outperformed non-mycorrhized plants in fresh and dry weight gain after acclimatization, whereas microplants mycorrhized in vitro outperformed those mycorrhized in vivo. The system described has potential for establishment of both aseptic mycorrhizae and gnotobiotic cultures involving mycorrhizae and helper bacteria, or selected biocontrol microorganisms, for both fundamental and applied studies.
\end{abstract}

Fragaria vesca / Glomus fistulosum / plant tissue culture

Résumé - Mise en place de la mycorhization dans des cultures in vitro en autotrophie de fraisier : comparaison avec l'inoculation de microplants in vivo. Il a été démontré la faisabilité de la mycorhization dans un système commercial de micropropagation en autotrophie de microplants de Fragaria vesca. Cela se traduit par une amélioration du développement de la plante. Les expériences décrites portent sur la comparaison entre microplantes mycorhizées in vitro et inoculées in vivo avec des spores non désinfectés. La mycorhization n'a pas altéré la photosynthèse et des différences dans le taux de colonisation in vivo et in vitro n'ont pas été observées. Les microplantes mycorhizées in vitro et in vivo ont acquis après acclimatation un poids en matière frâiche et sèche supérieur à celui des témoins, tandis que celles mycorhizées in vitro étaient de meilleure qualité que celles mycorhizées in vivo. Le système décrit est potentiellement intéressant pour établir des cultures aseptiques et gnotobiotiques avec des champignons mycorhizogènes et des bactéries helper ou des microorganismes selectionnés pour le biocontrol et cela aussi bien pour des études fondamentales qu'appliquées.

Fragaria vesca / Glomus fistulosum / micropropagation

* Correspondence and reprints 


\section{INTRODUCTION}

Micropropagation represents a potential application niche for arbuscular mycorrhizal (AM) fungi for the following reasons: i) microplants often show symptoms of vitrification (syn hyperhydricity), ie, they have poorly developed cuticles and non- or partially functional stomata which results in drought stress at acclimatization in vivo; ii) microplants, as a consequence of vitrification, can have poorly developed constitutive disease resistance, with hypolignification and reduced phytoalexin content and iii) aseptic microplants represent a 'biological vacuum' available for promiscuous colonization by environmental microorganisms including facultative pathogens. Given these points, a priori, inoculation with $A M$ in vitro would appear to offer solutions to both the above quality issues in micropropagation and to problems in AM application, eg, uncertainty regarding the influence of environmental microorganisms on the inoculation stage (see Lovato et al, 1996; Cassells, 1997).

AM fungi have been reported to confer protection against biotic and abiotic stresses (Gianinazzi and Schuepp, 1995). Conventionally, their exploitation in bioprotection has been by application to seedlings and vegetative propagules. Inoculation is based on the incorporation of $A M$ propagules in the region of the plant roots. As the AM inoculum is usually produced on plant roots in the environment it is non-sterile. Indeed, some of the contaminating microorganisms have been postulated to have a 'helper' role in mycorrhizae (Azcón-Aguilar et al, 1986).

The application of bioprotectant microorganisms, both biocontrol and growth-promoting rhizosphere bacteria, and mycorrhizal fungi, to plants is the subject of extensive current research (see eg, Gianinazzi and Schuepp, 1995). This work has extended to the inoculation of microplants. Wang et al (1993), for example, showed beneficial effects in the weaning of microplants of three ornamental species, gerbera, nephrolepis and syngonium, following inoculation with Glomus intraradices and $G$ vesiculiferum. Attempts, however, to inoculate in vitro cultures are influenced by the inhibitory effects of high osmotic pressure of the salts and high sucrose in Murashige and Skoog medium (Murashige and Skoog, 1962) and other common plant tissue culture media (Mosse, 1959; Hepper, 1979; Siqueira et al, 1982). Furthermore, Murashige and Skoog (1962) medium is a substrate for many environmental bacteria and fungi (Cassells
$1987,1997)$ and consequently, is an unsuitable substrate for inoculation with bacterially contaminated inoculum, as usually employed, or for studies on co-inoculation with $A M$ and helper or potential biocontrol bacterial inoculants, as the contaminants are likely to overgrow the culture causing microplant death (Cassells, 1987, 1997).

For this reason, we have sought an alternative plant tissue culture system that would allow inoculation with unsterile $A M$ inoculum and would also facilitate studies on co-inoculation with AM and bacteria. A prerequisite of the culture system was that it would result in the production of good quality microplants and the question posed was whether, under these circumstances, mycorrhization could be shown to confer further quality benefits on the microplants. The control for the model was good quality microplants, ie, non-vitrified, conventionally produced on mixotrophic culture medium (Cassells and Roche, 1994; Cassells and Walsh, 1994) and inoculated with $\mathrm{AM}$ at acclimatization.

The basis of the system that will be described here, is that the microplants must be produced autotrophically in vitro so that the system is free of carbon sources that would support bacterial overgrowth of the cultures. A second element of the system is the substitution of the support material, agar, which is of variable composition and may contain high salt, with inert polyurethane foam. The latter provides improved root aeration that may also benefit mycorrhization (Letacon et al, 1983) and also facilitates the removal of plants for examination of the roots with minimum disruption of the root system.

\section{MATERIALS AND METHODS}

\section{Mixotrophic micropropagation}

Microplants of Fragaria vesca $L$ were established via aseptic seed germination as described previously (Mark and Cassells, 1996). As a control, microshoots were rooted on 1/2 strength Murashige and Skoog (1962) medium (cat no 26-100-24, Flow Laboratories, Irvine, UK) containing $3 \% \mathrm{w} / \mathrm{v}$ sucrose, $0.1 \mathrm{mg} \cdot \mathrm{L}^{-1}$ indolebutyric acid and $7 \mathrm{~g} \bullet \mathrm{L}^{-1}$ agar, at $\mathrm{pH} 5.8$, in Magenta culture vessels (Sigma Chemical Co, Poole Dorset, UK). Media were sterilized by autoclaving at $105 \mathrm{Pka}, 121{ }^{\circ} \mathrm{C}$ for $15 \mathrm{~min}$. The growth room conditions were: photosynthetic photon flux $30 \mu \mathrm{mol} \mathrm{m} \mathrm{m}^{-2}$ $\mathrm{s}^{-1}, 16 \mathrm{~h}$ day; $22 \pm 1{ }^{\circ} \mathrm{C}$; relative humidity day $86 \%$, night $100 \%$. After 8 weeks the microplants were transferred to weaning trays in the glasshouse for acclimatization for a further 4 weeks before the microplants were potted up. 


\section{Phototrophic micropropagation}

Microshoots after 2 weeks on rooting medium as just described, were transferred to polyurethane foam (Plant Biotechnology [UCC], Cork, Ireland) imbibed with Enshi mineral nutrients and grown on in the growth room. The polyurethane foam had a density of $16 \pm 1$ $\mathrm{kg} \mathrm{m}^{-3}$ and a hardness of $72.5 \pm 12.5 \mathrm{~N}$. The composition of the Enshi mineral medium was $492 \mathrm{mg} \cdot \mathrm{L}^{-1}$ $\mathrm{MgSO}_{4} \cdot 7 \mathrm{H}_{2} \mathrm{O}, 944 \mathrm{mg} \cdot \mathrm{L}^{-1} \mathrm{Ca}\left(\mathrm{NO}_{3}\right)_{2}, 808 \mathrm{mg} \cdot \mathrm{L}^{-1}$ $\mathrm{KNO}_{3}, \mathrm{NH}_{4} \mathrm{H}_{2} \mathrm{PO}_{4} 152 \mathrm{mg} \cdot \mathrm{L}-1,19.5 \mathrm{mg} \cdot \mathrm{L}^{-1}$ Fe.EDTA, $2.82 \mathrm{mg}^{\circ} \mathrm{L}^{-1} \mathrm{H}_{3} \mathrm{BO}_{3}, 2.02 \mathrm{mg} \cdot \mathrm{L}^{-1} \mathrm{MnSO}_{4}, 0.22 \mathrm{mg} \cdot \mathrm{L}^{-1}$ $\mathrm{ZnSO}_{4}, 0.078 \mathrm{mg} \cdot \mathrm{L}^{-1} \mathrm{CuSO}_{4}, 0.021 \mathrm{mg} \cdot \mathrm{L}^{-1} \mathrm{NaMoO}_{4}$, $\mathrm{pH}$ 6.2. Polyurethane foams were used, cut into $6 \times 6$ $\mathrm{cm}$ squares, $1.5 \mathrm{~cm}$ in depth, to fit the Magenta vessel. The squares were divided into cells $2 \times 2 \times 1.5 \mathrm{~cm}$ which pulled apart by tear-strips. Each cell had a vertical $2 \mathrm{~mm}$ cut in the centre into which the explant was inserted (see fig 1). Foams were imbibed by immersion in culture medium with squeezing. The imbibed squares were then transferred to Magenta vessels and autoclaved with the Magenta lid in position. Each Magenta vessel contained four propagules and was sealed with the Magenta lid; culture vessels were positioned in a randomized replicate block. There were either 20 or 50 replicated per treatment (see later). The culture and acclimatization periods were as described earlier.

\section{Mineral analysis}

Samples were air-dried at $40{ }^{\circ} \mathrm{C}$ and then ground to pass through a $1 \mathrm{~mm}$ mesh. The samples were digested in nitric acid using a microwave digestion system and closed teflon digestion vessel. Sodium and potassium were determined by flame photometry. Calcium,

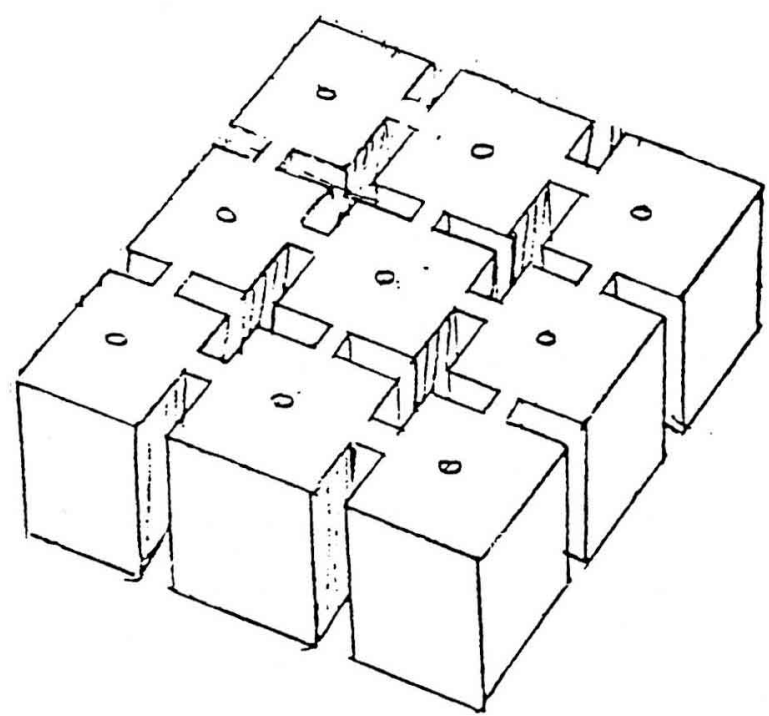

Fig 1. An illustration of the polyurethane foam. The foam squares measure $6 \times 6 \mathrm{~cm}$ surface area to fit into the Magenta culture vessel and are $1.5 \mathrm{~cm}$ thick. They are recut into nine cells $2 \times 2 \times 1.5 \mathrm{~cm}$ which pull apart by tear-strips. Each cell has a precut central planting hole. magnesium, phosphorus, manganese, aluminium, zinc, copper, boron, molybdenum and sulphur were determined by inductively-coupled plasma emission spectroscopy (Boumans, 1987; Elan 500, Foss Electrical Ltd, Dublin, Ireland). The distilled water used in the investigation contained $10.2 \mathrm{mg}^{\circ} \mathrm{L}^{-1}$ sodium; 1.5 $\mathrm{mg} \cdot \mathrm{L}^{-1}$ potassium; $0.03 \mathrm{mmg} \cdot \mathrm{L}^{-1}$ magnesium; and 0.2 $\mathrm{mg} \cdot \mathrm{L}^{-1}$ calcium. The concentrations of other ions were insignificant.

\section{Measurement of photosynthetic activity}

Photosynthesis was measured by infrared gas analysis using the apparatus described by Parkinson et al (1980). The custom-built measuring chamber was a $500 \mathrm{~mL}$ Kilner jar (a wide-necked vessel with a flat glass top that is held in place with a screw sealing ring; the insertion of a rubber $\mathrm{O}$-ring between the lid and the rim of the base ensures an air-tight seal) where the lid was modified to house inlet and outlet ports for the carbon dioxide supply. The lid also provided the support for a humidity sensor, photocell, thermister and fan. The system was manufactured by PP Systems (Cambridge, UK). Cultures were grown as described and transferred to the above chamber for measurement of photosynthesis. Six replicate cultures were determined for each treatment; there were four microplants in each culture.

\section{Determination of dry weights}

Dry weights were determined by infrared drying using a Mettler LJ 16 moisture analyzer (Mettler-Toledo AG, Greifensee, Switzerland).

\section{$A M$ spore germination assay}

A Glomus fistulosum isolate, registered as BEG31 in the 'Banque Européenne des Glomales' (INRA, Dijon, France), grown on the roots of Fragaria $x$ ananassa Duchesne 'Senga Sengana', was obtained from the Agricultural Research Centre, Laukaa, Finland. The inoculum was a mixture of mycorrhizal strawberry root pieces with adhering hyphae, spores, sand and vermiculite. This inoculum was bulked up in growth substrate (see later for composition) on the roots of the onion (Allium cepa) and had an approximate inoculum density of 255 spores $\mathrm{g}^{-1}$ of air-dried inoculum. The standardized inoculum was air-dried at room temperature and stored at $-20^{\circ} \mathrm{C}$, in the dark for 6 weeks before use.

Prior to use, the root material was allowed to equilibrate at room temperature for $24 \mathrm{~h}$ and the spores were isolated by wet sieving. Individual, true-to-type spores were selected and placed on water agar (10 $\mathrm{g} \bullet \mathrm{L}^{-1}, \mathrm{pH}$ 6.2) in petri dishes (the control) or were placed on polyurethane foam imbibed with the respective 
mineral nutrient solution, as appropriate. Ten spores were positioned in each container and there were 50 replicates of each treatment. The spores were incubated in the dark for 2 weeks at $22 \pm 1{ }^{\circ} \mathrm{C}$ and then examined by microscope (x 400).

\section{Mycorrhizal inoculation in vivo}

A peat-based growth substrate was used, consisting of a mixture of peat (medium grade; Bórd na Móna, Dublin, Ireland), sand and vermiculite, $8: 1: 1, v / v / v$, fertilized with 9 month $\left(1 \mathrm{~g} \bullet \mathrm{L}^{-1}\right)$ Osmocote Plus (GraceSierra International BV, Heerlen, the Netherlands) and limed $\left(5 \mathrm{~g} \cdot \mathrm{L}^{-1}\right)$ to a $\mathrm{pH}$ of 6.2 . The mix was steam sterilized at $121^{\circ} \mathrm{C}$ for $1 \mathrm{~h}$ on 3 successive days (Vestberg, 1992) before it was added to sterilized weaning trays $(36.5 \times 36.5 \times 56 \mathrm{~mm})$. In all cases the mix was allowed to cool to room temperature before the Osmocote and lime were added.

The clones were inoculated at weaning, by adding 1 $\mathrm{mL}$ of rehydrated inoculum directly to the planting hole, prior to planting in steam-sterilized compost. Weaning plants were then transplanted to $1 \mathrm{~L}$ plastic pots. The microplants were established and grown under glass, at ambient temperature with a $16 \mathrm{~h}$ photoperiod (high pressure sodium lamps 400 watts, 290/240 volts; Thermoforce Ltd, Camplex Plantcare Division, Essex, UK). The bases of the plastic pots were covered with plastic to prevent movement of mycorrhizal fungi, due to watering, from one plant to another.

\section{Mycorrhizal inoculation in vitro}

Strawberry microplants were taken from the agar-rooting medium and the roots carefully washed free of contaminating agar medium. They were placed in the planting holes in the polyurethane foam (see fig 1), four microplants per Magenta vessel and the unsterile spores placed adjacent to the planting hole, at a density of 0 (control) 2, 4, 6, 8 and 10 spores per microplant. Fifty replicates were set up for each treatment. The plants were incubated in the growth room at $3 \mu \mathrm{M} \mathrm{m}^{-2}$ $\mathrm{s}^{-1}$ for 2 weeks and then transferred to $30 \mu \mathrm{M} \mathrm{m}^{-2} \mathrm{~s}^{-1}$ for the rest of the in vitro culture period (other growth room parameters as described earlier). Two microplants were harvested at random from each treatment, weekly for 7 weeks. The root samples were pooled and subsamples collected for microscopic examination.

\section{Measurement of mycorrhizal colonization}

Colonized strawberry roots were cleared in $10 \% \mathrm{KOH}$ overnight and stained with $0.05 \% \mathrm{w} / \mathrm{v}$ trypan blue in lactophenol (Phillips and Hayman, 1970). Percentage root colonization was calculated using the grid line intersect method (Giovannetti and Mosse, 1980).
Further information on mycorrhizal colonization was obtained using a compound microscope at a total magnification of $\times 100$ (McGonigle et al, 1990).

\section{Statistical analysis}

The Mann-Whitney U-test and the Kruskal-Wallis statistical test for non-parametric data were used, Minitab version 8.2 and Minitab for Windows, Release 10.0. Dunn's multiple comparison test was also used.

\section{RESULTS AND DISCUSSION}

\section{Characteristics of inoculation in vivo}

In vivo inoculation showed a dose response; increasing plant vigour (fig 2) resulted from increased inoculum potential. In parallel with the growth-promoting effect, percentage root colonization also increased with the increase in inocu$\mathrm{lum}$, with a plateau at between 1 and $2 \mathrm{~g}$ inoculum per $50 \mathrm{~mL}$ of compost in the root environment (fig 3). This is equivalent to about 170 spores per microplant based on a spore viability of approximately $50 \%$. At the lowest dilution of inoculum, that is, equivalent to less that two spores per root system, no growth effect was observed and no mycorrhizal colonization was detected on microscopic examination.

The mean percentage root colonization in plants in steam-sterilized compost using unsterile inoculum at $1 \mathrm{~g}$ per $50 \mathrm{~mL}$ of compost in the planting hole was significantly higher than for inoculation with the same inoculum in unsterile compost, namely $63.42 \pm 2.5$ (median 62.12) and $69.82 \pm 1.88$ (median 70.32), respectively, where $w=291.0$ and $p=0.0347$. This may indicate that

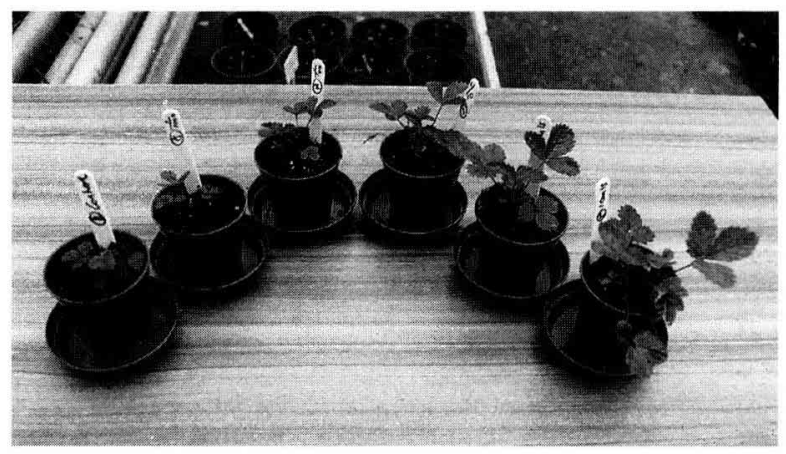

Fig 2. A photograph of the inoculum dose response. The inoculum was placed in the planting hole as described in the text. The inoculum dilutions in compost were (left to right) 0 (control), $0.001,0.01,0.1,1$ and $2 \mathrm{~g}$ per $50 \mathrm{~mL}$ of compost, respectively. One gramme of inoculum contained about 255 spores at approximately $50 \%$ viability. 


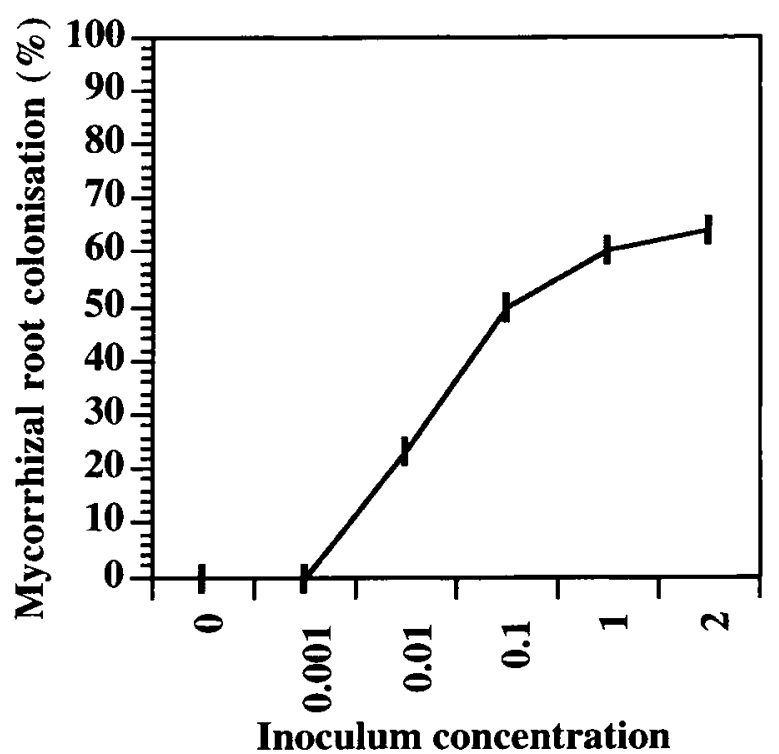

Fig 3. The relationship between inoculum and mean percentage root colonization. The inoculum was prepared as described in figure 2 . colonization is influenced by competition from resident compost microorganisms. Alternatively, steam sterilization may have influenced mineral availability, stimulating the mycorrhizae.

\section{Germination of AM spores in culture media}

The germination percentage rates for spores germinated on water agar $\left(6 \mathrm{~g}^{\cdot \mathrm{L}^{-1}}\right.$ agar; Code A7002, Sigma Chemical Co, Poole, Dorset, UK), and in polyurethane foam on Enshi mineral formulation were $54.44 \pm 5.27$ and $60 \pm 3.2$, respectively, confirming that neither the polyurethane foam nor mineral solutions were inhibitory to spore germination. A chemical analysis of the agar and polyurethane foams used is given in table I from which it can be seen that the polyurethane foam contains little ion contamination in comparison to the agar. Given that agar is a natural product, showing batch-to-batch variation (Cassells and Collins, 1997), polyurethane foam provides a uniform material for investigations where, as here, ion content is important.

Table I. Mineral analysis of the agar and polyurethane foam used.

$\begin{array}{lll}\text { Macro-elements } & & <0.01 \\ \text { Sodium } & 57 & <0.01 \\ \text { Potassium } & 5 & <0.01 \\ \text { Magnesium } & 6 & 2 \\ \text { Calcium } & 7 & 0.01 \\ \text { Phosphorus } & 2 & 2\end{array}$

\section{Micro-elements}

Iron

Manganese

Aluminium

Copper

Boron

Zinc

Molybdenum

Cobalt

lodine

Chromium

Cadmium
0.2

0.01

0.09

0.02

0.39

0.02

$<0.01$

$<0.01$

1.2

$<0.01$

$<0.01$
0.01

$<0.01$

0.19

$<0.01$

$<0.01$

0.09

$<0.01$

$<0.01$

0.03

$<0.01$

$<0.01$

The mineral content is expressed, for comparative purposes, on the basis of the amount of the respective support materials used in preparing $1 \mathrm{~L}$ of culture medium, namely, per $6 \mathrm{~g}$ agar and per $22 \mathrm{~g}$ polyurethane foam. 


\section{Characteristics of inoculation in vitro}

$G$ fistulosum colonization was observed at inoculum spore densities of four spores per microplant and above. There was no increase in mean percentage root colonization with an increase in inoculum in culture. At infectious inoculum levels, what appeared to be penetration points, appressoria and intercellular hyphae were detected from 2 weeks after inoculation. At 4 weeks, arbuscules were visible. Root hair abundance increased with increasing inoculum density. No vesicles were produced in vitro in the polyurethane foams.

Eight weeks after inoculation the microplants were transferred to the glasshouse for acclimatization. Mean total and arbuscular percentage colonization after acclimatization were $8.18 \pm$ 1.24 and $5.26 \pm 1.6$, respectively.

\section{Effect of inoculation in vitro on photosynthesis}

The net photosynthetic rates of microplants in vitro and at varying times after establishment in vivo is shown in figure 4 . The data show that the rates of photosynthesis in microplants in mixotrophic culture, and mycorrhized and non-mycorrhized microplants in phototrophic culture in foam, did not differ in vitro. During and after acclimatization, the net photosynthetic rate increased in all treatments for approximately 5 weeks, at which time it levelled off (fig 4).

\section{Effects of mycorrhization in vitro and in vivo on microplant establishment and growth}

The mean shoot fresh and dry weights of microplants mycorrhized in vitro and in vivo, determined 4 months after the establishment of the in vitro cultures, are given in figure 5 from which it can be seen that both parameters are significantly increased in the in vitro mycorrhized plants compared to the controls.

\section{CONCLUSION}

The main objective of research in this laboratory has been to develop procedures to improve the quality of plants produced in micropropagation. This has involved improvements in culture vessel design and in the search for alternative supports to agar. The use of differentially permeable vessel lids and the substitution of the gel support, agar, with a more porous material, polyurethane, have lead to quality improvements (Cassells and Roche, 1994; Cassells and Walsh, 1994). It has been demonstrated that AM fungi can further improve the quality of Fragaria vesca microplants at and after acclimatization. This result has been repeated with $F$ ananassa cv Elvira (Murphy et al, 1997). Elsewhere, it has been shown that these benefits extend to field performance (Mark and Cassells, 1996).

In this study it has been shown that in vitro mycorrhization, in phototrophic culture, has several advantages over in vivo microplant inoculation. First, it appears to be more efficient in that inoculation can be achieved at, or near, the minimum inoculum concentration of two viable spores

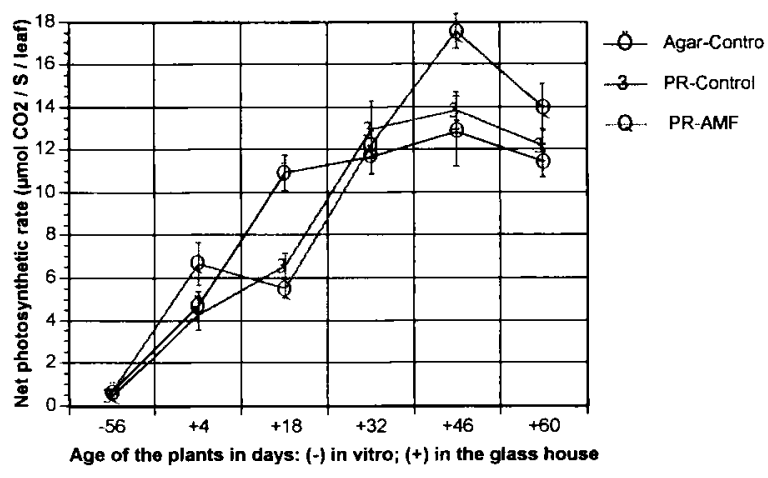

Fig 4. The net rate of photosynthesis measured in vitro and at varying times during and after acclimatization in the glasshouse. Photosynthesis in vivo was measured by infrared gas analysis using the apparatus described by Parkinson et al (1980); for in vitro measurements a modified Kilner jar was used instead of the standard chamber (see Materials and Methods section).

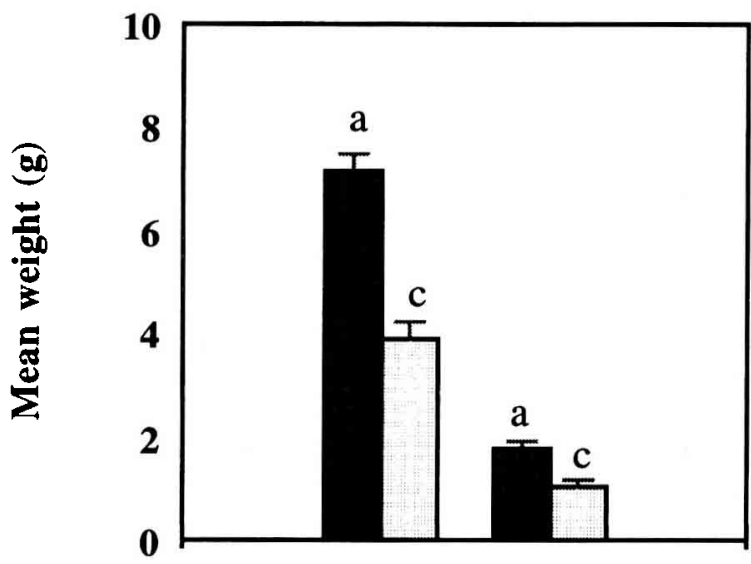

Fig 5. The mean fresh and dry weights of microplants in vivo taken 4 months after the initiation of the cultures. The first pair of bars are the data for the fresh weights; the second are for the corresponding dry weights (a: mycorrhization in vitro; c: mycorrhization in vivo). 
per microplant. Second, inoculation can be achieved without competition from environmental microorganisms. The latter effects were inferred here from the comparison between inoculation in vivo in sterilized versus unsterilized substrate. More importantly, it should be possible both to inoculate aseptic plants with aseptic spores of mycorrhizal fungi, again without interference, and to co-inoculate with helper bacteria and mycorrhizal fungi to establish gnotobiotic systems for in vitro and in vivo studies. That the latter is possible is due to the carbon-source independence of phototrophic micropropagation. In conventional heterotrophic micropropagation a carbon source is essential, albeit as here, the cultures may become mixotrophic, ie, capable of photosynthesis, as growth and development occurs in vitro.

In summary, the tissue culture system described has application both in commercial micropropagation and in the maintenance, under aseptic conditions while maintaining host specificity, of mycorrhizal fungal isolate collections. Furthermore, it will facilitate molecular and biochemical studies of mycorrhizae free of inference from complex environmental factors.

\section{ACKNOWLEDGMENTS}

The authors are grateful to $M$ Vestberg for inoculum of BEG31 and for helpful advice and to C Walsh for technical assistance.

\section{REFERENCES}

Azcón-Aguilar C, Diaz-Rodriquez RM, Barea JM (1986) Effect of soil microorganisms on spore germination and growth of the vesicular arbuscular mycorrhizal fungi. Trans Br Mycol Soc 86, 337-340

Boumans PWJM (1987) Inductively-coupled Plasma Emission Spectroscopy. J Wiley \& Sons, New York, NY, USA

Cassells AC (ed) (1987) Bacterial and bacteria-like contaminants of plant tissue cultures. Acta Hort 225

Cassells AC (1997) Pathogen and Microbial Contamination Management in Micropropagation. Kluwer, Dordrecht, the Netherlands (in press)

Cassells AC, Roche T (1994) The influence of the gas permeability of the vessel lid and growth-room light intensity on the characteristics of Dianthus microplants in vitro and ex vitrum. In: Physiology, Growth and Development of Plants in Culture (PJ Lumsden, JR Nicholas, WJ Davies, eds), Kluwer, Dordrecht, the Netherlands, 204-214
Cassells AC, Walsh C (1994) The influence of the gas permeability of the culture vessel lid on calcium uptake and stomatal function in Dianthus microplants. Plant Cell Tiss Org Cult 37, 171-178

Cassells AC, Collins IM (1997) Characterization and comparison of agars and other gelling agents for plant tissue culture use. In Vitro Dev Biol (in press)

Gianinazzi S, Schuepp H (1995) Impact of Arbuscular Mycorrhizas on Sustainable Agriculture and Natural Ecosystems. Birhauser Verlag, Basel, Switzerland

Giovannetti M, Mosse B (1980) An evaluation of techniques for measuring vesicular-arbuscular mycorrhizal infection in roots. New Phytol 84, 489-500

Hepper CM (1979) Germination and growth of Glomus caledonium spores: the effects of inhibitors and nutrients. Soil Biol Biochem 14, 269-277

Letacon F, Skinner FA, Mosse B (1983) Spore germination and hyphal growth of a vesicular-arbuscular mycorrhizal fungus Glomus mosseae (Gerdemann and Trappe) under decreased oxygen and increased carbon dioxide concentration. Can J Microbiol 29, 1280-1285

Lovato PE, Gianinazzi-Pearson V, Trouvelot A, Gianinazzi S (1996) The state of art of mycorrhizas and micropropagation. Adv Hort Sci 10, 46-52

Mark GL, Cassells AC (1996) Genotype-dependence in the interaction between Glomus fistulosum, Phytophthora fragariae and the wild strawberry (Fragaria vesca). Plant Soil 185, 233-239

McGonigle TP, Miller MH, Evans DG, Fairchild GL, Swan JA (1990) A method which gives an objective measure of colonization of roots by vesicular-arbuscular mycorrhizal fungi. New Phytol 115, 495-501

Mosse B (1959) The regular germination of resting spores and some observations on the growth requirements on an endogone sp causing vesiculararbuscular mycorrhizae. Trans Br Mycol Soc 42, 273-286

Murashige T, Skoog $F$ (1962) A revised medium for rapid growth and bioassay with tobacco tissue culture. Physiol Plant 15, 473-497

Murphy J, Mark GL, Periappuram C, Walsh C, Cassells AC (1997) In vitro mycorrhization of strawberry. In: Contamination Management in Plant Tissue Culture (AC Cassells, ed), Kluwer, Dordrecht, the Netherlands (in press)

Parkinson KJ, Day W, Leach JE (1980) A portable system for measuring the photosynthesis and transpiration of graminaceous leaves. J Exp Bot 31, 14411453

Phillips JM, Hayman DS (1970) Improved procedures for clearing roots and staining parasitic and vesicular-arbuscular mycorrhizal fungi for rapid assessment of infection. Trans Br Mycol Soc 55, 158-160

Siqueira JO, Hubbell DH, Schenk NC (1982) Spore germination and germ-tube growth of a vesiculararbuscular mycorrhizal fungus in vitro. Mycologia 74, 952-959

Vestberg M (1992) The effects of vesicular-arbuscular mycorrhizal inoculation on the growth and root colo- 
nization of 10 strawberry cultivars. Agric Sci Finn 1, 527-534

Wang H, Parent S, Gosselin A, Desjardins Y (1993) Vesicular-arbuscular mycorrhizal peat-based sub- strates enhance symbiosis establishment and growth of three micropropagated species. J Am Soc Hort Sci 118, 896-901 